\title{
Pemanfaatan Cloud Computing untuk Enterprise Resources Planning di Indonesia
}

\author{
Asniar $^{1}$, Siska Komala Sari ${ }^{2}$ \\ ${ }^{1}$ Prodi Komputerisasi Akuntansi Fakultas Ilmu Terapan, Universitas Telkom \\ ${ }^{2}$ Prodi Manajemen Informatika Fakultas Ilmu Terapan, Universitas Telkom \\ ${ }^{1,2}$ Jl. Telekomunikasi, Dayeuh Kolot Kab. Bandung 40257, Indonesia \\ asniar@telkomuniversity.ac.id, siska@tass.telkomuniveristy.ac.id
}

\begin{abstract}
Abstrak - Cloud Computing adalah sebuah topik yang telah mendapatkan momentum dalam beberapa tahun terakhir. ERP (Enterprise Resource Planning) adalah struktur sistem informasi yang digunakan untuk mengintegrasikan proses bisnis dalam perusahaan manufaktur/jasa yang meliputi operasional dan distribusi produk yang dihasilkan. Selama ini, aplikasi ERP dan cloud computing berjalan sendiri-sendiri, belum pernah ada yang menyatukannya untuk kepentingan bisnis perusahaan. Aplikasi ERP untuk Cloud Computing (ERP Cloud) akan menguntungkan perusahaan kecil karena dapat menurunkan hambatan umum terutama berkaitan dengan biaya investasi yang besar untuk penggunaan Sistem ERP pada umumnya. Usaha Kecil Menengah (UKM) dapat memiliki akses penuh atas sistem ERP yang sesuai dengan proses bisnis perusahaan tanpa perlu membeli keseluruhan aplikasi ERP atau menyewa konsultan TI yang mahal. Dengan kondisi Indonesia yang masih didominasi oleh perusahaan dengan skala kecil menengah maka di Indonesia sangat diperlukan pemanfaatan jasa could computing untuk ERP perusahaan sehingga semakin banyak perusahaan yang memanfaatkan aplikasi ERP dengan biaya yang lebih ringan.
\end{abstract}

Kata kunci-ERP, Cloud Computing, Cloud Service, ERP Cloud

Abstract-Cloud Computing is a topic that has gained momentum in recent years. ERP (Enterprise Resource Planning) system is the structure of the information used to integrate business processes in manufacturing / services which include operational and distribution of the resulting product. During this time, ERP and cloud computing applications running on their own, no one has ever put it together for the benefit of the company's business. Applications for Cloud Computing ERP (ERP Cloud) will provide benefits for small companies because it can reduce common barriers mainly related to the large investment costs for the use of ERP systems in general. Small and Medium Enterprises (SMEs) can have full access to the ERP system that matches the company's business processes without the need to purchase the entire ERP application and hire an expensive IT consultants. The current state of small and medium scale companies are still dominant in Indonesia. Utilization of cloud computing services for the enterprise ERP is needed because the cost is affordable for small and medium companies.

Keywords- ERP; Cloud Computing; Cloud Service; ERP Cloud

\section{PENDAHULUAN}

Studi saat ini menunjukkan bahwa meningkatnya jumlah perusahaan sedang mengevaluasi keuntungan yang dijanjikan dan mempertimbangkan memanfaatkan layanan cloud [1]. Efektivitas biaya merupakan salah satu faktor yang signifikan pada pengambilan keputusan implementasi teknologi baru, terutama Cloud Computing. Faktor-faktor yang signifikan bisa menjadi masukan yang signifikan bagi pengambil keputusan dalam mengambil keputusan pada penerapan teknologi baru, terutama di Cloud Computing.

Sebagai bagian dari lingkungan bisnis elektronik, perubahan yang lebih cepat di bawah globalisasi juga mempengaruhi perusahaan termasuk perusahaan kecil dan menengah juga perlu mengubah bisnis mereka. Dengan perkembangan perusahaan menjadi lebih besar dan lebih besar, warisan sistem bisnis lama tidak cukup fleksibel untuk beradaptasi dengan kemungkinan perubahan dan kejanggalan antara bisnis dan sistem informasi dalam organisasi perusahaan. Oleh karena itu, perusahaan sebagian besar menggunakan suatu Enterprise Resource Planning (ERP) sistem untuk meningkatkan inti kompetensi [2].

Implementasi sistem ERP bukanlah investasi IT yang murah dan mudah. Masalah utama yang banyak dihadapi oleh perusahaan dalam pemilihan ERP adalah biaya. Harga aplikasi ERP yang relative mahal menjadi pertimbangan utama dalam pemilihan paket ERP yang digunakan. Mekipun ada ERP yang open source, namun dalam kenyataannya relatif sulit untuk diimplementasikan. Harga Aplikasi ERP yang mahal adalah faktor utama yang mempengaruhi perusahaan tidak menggunakan Aplikasi ERP. Padahal Perusahaan akan mendapatkan keuntungan seperti 
meningkatnya market share karena masuknya perusahaan melalui media internet membuat pemasaran tidak hanya terbatas dari Indonesia.

"Sebagai akibat dari krisis keuangan dan ekonomi 2008-2009, perusahaan telah mencari cara untuk mengkonsolidasikan infrastruktur ICT dan jasa untuk meningkatkan pengembalian investasi. Cloud computing muncul sebagai pilihan yang menarik " [1]. Cloud computing menjadi sebuah konsep yang mendapat perhatian selama tahun terakhir. Dalam banyak hal bukanlah sebuah fenomena yang sama sekali baru karena menggabungkan elemen dari IT outsourcing yang telah tersedia selama lebih dari 10 tahun (misalnya penyediaan perangkat lunak melalui Internet atau perumahan infrastruktur TI untuk klien perusahaan). Ada tanda-tanda yang jelas bahwa kepentingan perusahaan dalam layanan cloud computing meningkat: "Permintaan untuk layanan cloud computing diperkirakan akan terus meningkat; menurut IDC, pasar untuk layanan komputasi awan akan tumbuh sekitar 40\% pada tahun 2010" [1].

Beberapa penulis berpendapat bahwa cloud computing merupakan cara masa depan menggunakan teknologi informasi dalam bisnis [3]. Mereka menunjukkan bahwa memperoleh daya komputer melalui internet dapat memiliki dampak besar pada keseluruhan industri komputer dan perusahaan terhindar dari tindakan menginstal perangkat lunak pada sistem operasional internal. Akibatnya, mereka tidak perlu membeli atau mempertahankan perangkat keras dan perangkat lunak yang hanya bisa disewa secara online.

Cloud computing merupakan tren baru di bidang komputasi terdistribusi dimana berbagai pihak dapat mengembangkan aplikasi dan layanan berbasis SOA (Service Oriented Architecture) di jaringan internet. Berbagai kalangan dapat menarik manfaat dari layanan cloud computing ini baik sebagai solusi teknologi maupun mendapatkan manfaat ekonomis darinya. Sementara sistem ERP merupakan pendukung proses inti di suatu perusahaan dan harus mencerminkan organisasi struktur perusahaan yang datang dalam berbagai ukuran dan spesialisasi. Paling penting, Sistem ERP biasanya melalui proses kustomisasi substansial sehingga cocok untuk kebutuhan perusahaan tertentu, dan secara elektronik terkait dengan perangkat lunak sistem lainnya (sistem warisan misalnya atau sistem mitra).

Kelayakan adaptasi sistem ERP ke lingkungan cloud perlu diatasi sebelum keputusan untuk cloud computing diambil. Sementara ada sedikit keraguan bahwa cloud computing dapat bermanfaat di bidang komputasi kantor dan kolaborasi berbagai group pekerjaan [3]. Karena itu menarik untuk meneliti berbagai bentuk operasi bisnis kompleks yang ditangani oleh sistem perangkat lunak (seperti sistem ERP) di lingkungan cloud untuk mengetahui manfaat penggunaan cloud computing pada model operasi sistem ERP termasuk peluang serta tantangan masa depan cloud computing untuk sistem ERP.

\section{METODOLOGI PENELITIAN}

Metodologi penelitian ini adalah pemahaman tentang Cloud Computing dan ERP (Enterprise Resources Planning) serta usulan kerangka kerja yang berkaitan dengan pemanfaatan cloud computing untuk ERP di Indonesia termasuk pembahasan tentang tantangan layanan cloud computing untuk sistem ERP.

\section{CLOUD COMPUTING}

Cloud computing merupakan bentuk online dari grid computing dan merupakan penerapan konsep komputasi terdistribusi yang lebih diarahkan pada jaringan internet [4]. Cloud computing kini merupakan istilah umum untuk segala sesuatu yang melibatkan jasa ter-host melalui internet.

Email yang tersedia dalam bentuk web mail merupakan contoh yang sangat kecil dari teknologi cloud computing. Dengan menggunakan layanan email seperti Gmail dan Yahoo Mail, orang tidak perlu lagi menggunakan outlook atau aplikasi desktop lainnya untuk email mereka. Membaca email dengan browser memungkinkan dilakukan di mana saja sepanjang ada koneksi internet.

Pada tahun 2007, layanan lain termasuk pengolahan kata, spreadsheet, dan presentasi telah dipindahkan ke dalam cloud computing. Google menyediakan pengolah kata, spreadsheet dan aplikasi presentasi di lingkungan komputasi yang awan dan terintegrasi dengan Gmail dan Google Calendar, menyediakan lingkungan kantor di web (atau di awan). Microsoft dan perusahaan lain juga bereksperimen dengan mengalihkan program-program ke cloud untuk membuatnya lebih terjangkau dan lebih mudah diakses oleh pengguna komputer dan internet. Dengan cloud computing, microsoft menggunakan perangkat lunak sebagai layanan dimana ini merupakan inovasi baru bagi kebanyakan orang di Microsoft.

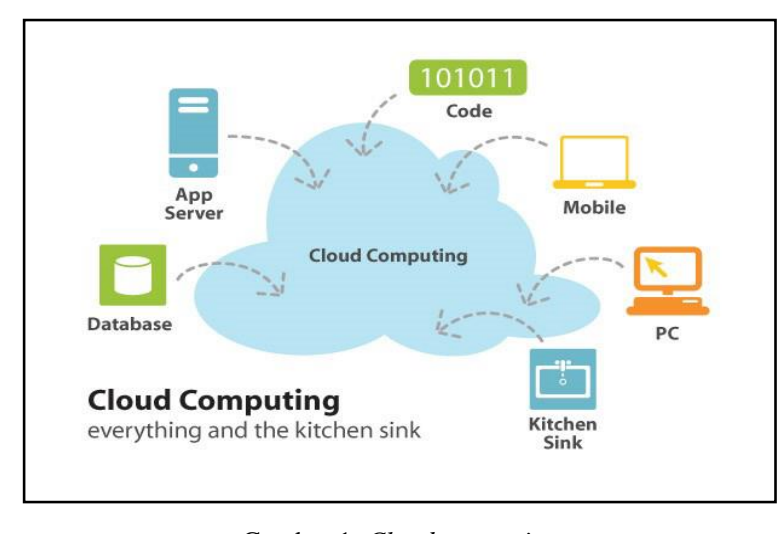

Gambar 1. Cloud computing 
Teknologi komputasi dan teknik pemrograman baru atau teknik pengembangan berubah dengan cepat. Cloud computing nampaknya membuat teknologi menjadi sangat mudah dan menjadikannya sesederhana mungkin dimata user. Perkembangan teknologi berbasis internet sangat pesat saat ini dengan blogging dan microblogging serta layanan media sosial yang bertujuan untuk menemukan cara baru membantu individu dan bisnis agar dapat berkomunikasi satu sama lain di lingkungan cloud computing.

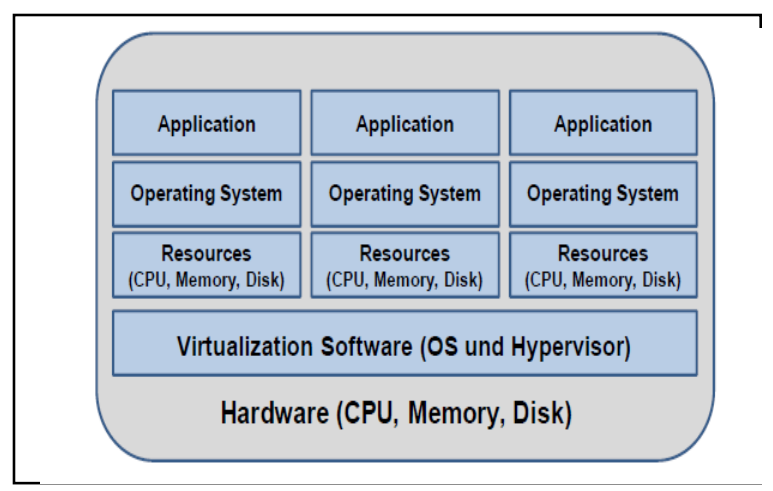

Gambar 2. Server Virtualization [5]

Sebuah konsep kunci untuk cloud computing adalah virtualisasi server. Gambar 2 menunjukkan sebuah server fisik yang telah dibagi menjadi tiga server virtual yang terpisah. Perangkat lunak virtualisasi (misalnya VMWare) menyediakan sumber daya yang diperlukan untuk server virtual. Setiap virtual Server memandang sumber daya sistem (seperti CPU, memori, dan disk) sebagai unik untuk mereka [5]. Topologi ini membantu mengalihkan disk mesin virtual dari satu sistem penyimpanan data ke penyimpanan data yang lain dengan tidak secara berkelanjutan serta dinamis menyeimbangkan penyimpanan beban kerja dengan performansi yang lebih baik [5].

Adapun tipe dari layanan cloud computing terdiri dari public cloud, private cloud, dan hybrid cloud. "Public Cloud" sering digambarkan sebagai "tersedia untuk semua orang" dan dijalankan oleh pihak ketiga [5]. Sementara kata "public" itu tidak benar-benar memberikan penjelasan tentang bagaimana akses publik ini secara teknis direalisasikan. Salah satu pilihan adalah penggunaan teknologi virtualisasi seperti diperlihatkan oleh gambar 3 dimana memperlihatkan penggunaan teknologi untuk berbagi server di antara banyak pengguna [6].

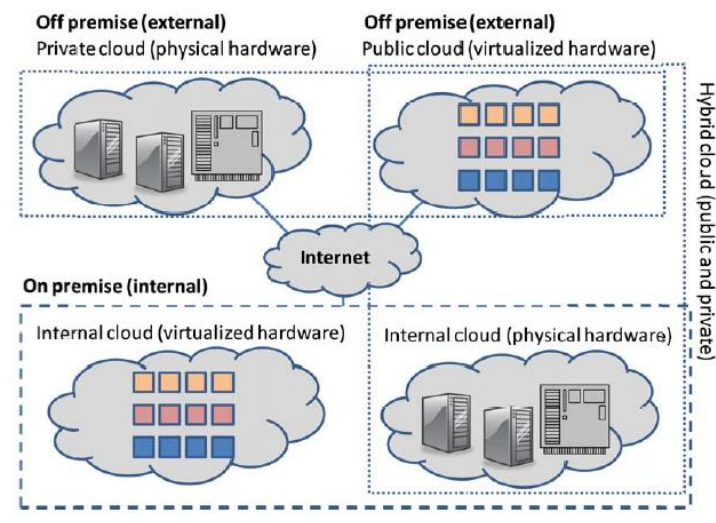

Gambar 3. Cloud Types [7]

Sebagai konsekuensi logis pengguna dari "private cloud" maka akan memiliki server fisik pada penggunaan eksklusif mereka [3]. Bahkan private cloud bisa memanfaatkan virtualisasi server (tapi eksklusif untuk perusahaan). Lingkungan virtualnya bisa disebut private cloud dan dioperasikan oleh pihak ketiga (eksternal cloud) atau perusahaan pengguna itu sendiri (internal cloud).

Penjelasan yang paling kontroversial adalah untuk "cloud hybrid". Beberapa melihatnya sebagai kombinasi fisik private server sebagai sumber daya permanen ditambah dengan kebutuhan untuk virtual public server [3]. Pandangan ini merupakan konsep yang paling berguna dari manajemen TI berdasarkan aspek skalabilitas dan struktur biaya dengan perspektif yang jelas [7]. Pendapat lain mengklaim bahwa hibrida menggabungkan dua cloud dengan entitas yang tetap unik namun yang terikat bersama-sama untuk memungkinkan ketersediaan data dan integrasi aplikasi [6] [8].

\section{ENTERPRISE RESOURCES PLANING (ERP)}

ERP (Enterprise Resource Planning) adalah struktur sistem informasi yang digunakan untuk mengintegrasikan proses bisnis dalam perusahaan manufaktur/jasa yang meliputi operasional dan distribusi produk yang dihasilkan. Sistem ERP adalah sebuah sistem yang mengintegrasikan dan mengotomatisasikan aktifitas perusahaan seperti bagian manufaktur, keuangan, dan manjemen rantai pasok [9]. Tujuan dari implementasi ERP adalah menyatukan semua divisi yang ada dalam perusahaan menjadi satu sistem yang dapat dikendalikan secara terpusat. ERP lebih ditujukan pada sistem back-office, dimana sistem ERP tidak bersentuhan secara langsung dengan konsumen.

Gambaran ERP adalah sebagai berikut.

- $\quad$ Sistem ERP adalah suatu paket perangkat lunak yang didesain untuk lingkungan pelanggan pengguna server, apakah itu secara tradisional atau berbasis jaringan. 
- Sistem ERP memadukan sebagian besar dari proses bisnis.

- Sistem ERP memproses sebagian besar dari transaksi perusahaan.

- $\quad$ Sistem ERP menggunakan database perusahaan yang secara tipikal menyimpan setiap data sekali saja.

- Sistem ERP memungkinkan mengakses data secara waktu nyata (real time).

- Dalam beberapa hal sistem ERP memungkinkan perpaduan proses transaksi dan kegiatan perencanaan.

- $\quad$ Sistem ERP menunjang sistem multi mata uang dan bahasa, yang sangat diperlukan oleh perusahaan multinasional.

- Sistem ERP memungkinkan penyesuaian untuk kebutuhan khusus perusahaan tanpa melakukan pemrograman kembali.

Pada umumnya, ERP dibangun sebagai sistem berbasis modul yang menangani proses manufaktur, logistik, distribusi, inventori, invoice, akuntasi perusahaan dan lain sebagainya. Dari modul-modul tersebut, maka aktivitas penjualan, pengiriman, produksi, manajemen persediaan, manajemen kualitas dan sumber daya manusia dapat dikontrol dengan baik dan informasi yang berhubungan dengan aktivitas tersebut dapat diperoleh dengan cepat.

ERP dibagi menjadi tiga modul utama, yaitu modul operasi, modul financial dan akuntansi, dan modul sumber daya manusia. Ketiga modul ini berjalan secara terpisah, sehingga perusahaan tidak harus mengimplementasikan ketiganya secara langsung. Meskipun begitu, ketiga modul tersebut berhubungan langsung dengan satu database terpusat. Misalnya ketika bagian penjualan menerima pesanan dari konsumen, bagian gudang langsung mengetahui dan mempersiapkan pesanan tersebut. Kemudian bagian akuntansi dapat melihat apakah barang pesanan sudah dikirim atau belum, sehingga dapat mempersiapkan tagihan untuk konsumen. Sistem ini akan menghemat banyak resource perusahaan, seperti waktu, biaya dan tenaga kerja. Semua orang dalam sistem dapat melihat data yang sama dan akan memperoleh informasi terbaru dari semua divisi dalam perusahaan.

\section{IMPLEMENTASI ERP DI INDONESIA}

Permulaan implementasi ERP di Indonesia ditandai dengan penggunaan SAP oleh Astra pada tahun 1990an. Pada masa itu, implementasi ERP belum dijalankan di sebagian besar perusahaan di Indonesia. Sebagian besar perusahaan masih dijalankan dengan cara tradisional, dalam artian pelaksanaan proses bisnisnya berjalan dengan cara konvensional. Pembukuan masih dilakukan secara tertulis, dan kalaupun ada penggunaan komputer, sebatas menggunakan perhitungan excel maupun modul yang berdiri per divisi.
Trend penggunaan ERP di Indonesia banyak dipengaruhi oleh banyaknya perusahaan asing yang mendirikan pabriknya di Indonesia. Secara otomatis, sistem informasi yang digunakan di perusahaan induk, juga digunakan di anak perusahaannya di Indonesia, dengan pertimbangan kemudahan integrasi dengan pusat [10].

Pada awal trend ERP masuk di Indonesia, banyak perusahaan yang berusaha untuk mengimplementasikan ERP secara built in, dimana perusahaan berusaha membangun sistem terintegrasinya dan kemudian untuk dijual ke perusahaan lain juga, dengan tujuan untuk mengubah divisi IT dari cost centre menjadi profit centre. Kemudian pada perkembangannya di tahun 2000an, mulailah bermunculan vendor IT, yang menyediakan jasa implementasi ERP di perusahaan.Produk ERP berkembang menjadi banyak model, dan mulai bermunculan variasi modul seperti CRM, QM, SRM dan lain sebagainya, pada tahun 2005an. Pada masa ini pula, perusahaan mulai merasakan dampak IT untuk membantu kinerja perusahaan.

Implementasi ERP membutuhkan persiapan yang matang, karena kesalahan implementasi akan mengakibatkan kerugian yang tidak sedikit. Tahap paling awal dari implementasi ERP adalah membangun proses bisnis yang baik. Tanpa proses bisnis yang baik, semua sistem informasi berbasis komputer dengan teknik apapun tidak akan mampu meningkatkan efisiensi dan efektivitas perusahaan tersebut. Selain itu, kesiapan karyawan akan perubahan sistem merupakan salah satu hal yang harus diperhitungkan. Rancangan ERP yang sempurna tidak akan membantu jika tidak dijalankan dengan baik. Yang harus diingat adalah tidak semua perusahaan membutuhkan ERP dalam sistemnya. Karena proses bisnis setiap perusahaan bersifat unik, sehingga ERP dalam satu perusahaan belum tentu dapat digunakan pada sistem di perusahaan yang lain, atau perbaikan proses bisnis dalam perusahaan cukup untuk meningkatkan efisiensi dan efektivitas.

Agar sebuah perusahaan dapat menerapkan konsep ERP dengan baik, setiap aspek dari organisasi, manusia, informasi, dan teknologi harus dipersiapkan dengan baik. Dengan demikian penerapan tata kelola perusahaan yang baik dapat diimplementasikan pada industri sehingga dapat meningkatkan daya saing di pasar.

\section{A. Komponen Yang Mempengaruhi Implementasi ERP}

Berikut akan komponen-komponen yang mempengaruhi implementasi ERP.

1) Pihak Manajemen dan Karyawan

Kesuksesan implementasi IT dalam perusahaan sangat membutuhkan dukungan dari pihak manajemen. Para eksekutif perusahaan harus memiliki pengertian bahwa IT membutuhkan strategi 
pengembangan yang dinamis dan berkesinambungan, IT harus berjalan seiring dengan proses bisnis perusahaan, selain itu pihak eksekutif harus membawa IT ke jalan yang sama dengan visi dan misi perusahaan.

Karyawan juga memegang peranan yang penting dalam keberhasilan implementasi ERP. Sebaiknya, sebelum implementasi dijalankan, karyawan dipersiapkan untuk perubahan besar yang akan terjadi, bila perlu karyawan diikut sertakan dalam tahap analisis proses bisnis, sehingga terbangun rasa memiliki yang kuat terhadap sistem baru. Dengan demikian, ketika implementasi benar-benar dijalankan, karyawan telah siap dan memiliki kemauan untuk belajar dan mendukung keberhasilan ERP tersebut. ERP tidak selalu identik dengan perampingan karyawan. Pemikiran ini yang dapat menyebabkan karyawan anti terhadap perubahan ke sistem ERP, karena merasa posisinya terancam dengan kemudahan yang ditawarkan ERP.

\section{2) Proses Bisnis}

Untuk membangun sistem ERP, proses bisnis harus disusun dengan jelas dan tepat. Tanpa proses bisnis yang benar, sistem apapun yang diterapkan tidak akan mampu memperbaiki keadaan perusahaan. Dalam membangun sistem ERP, sebaiknya batasan sistem yang akan dibangun jelas, sehingga implementasi ERP tidak berkembang ke hal-hal yang tidak diperlukan.

\section{3) Vendor}

Vendor adalah perusahaan yang menyediakan paket sistem ERP yang akan diimplementasikan di perusahaan. Selain menyediakan software dan hardware, vendor juga harus memberikan pelatihan pada karyawan perusahaan yang menggunakan jasanya agar karyawan terbiasa dengan sistem IT yang baru. Vendor juga sebaiknya memastikan sistem yang baru berjalan ini sesuai dengan permintaan dan proses bisnis perusahaan. Vendor yang baik memiliki respon yang cepat terhadap masalah yang dihadapi perusahaan maupun error yang terjadi pada sistem. Sebelum menentukan vendor mana yang akan digunakan, sebaiknya perusahaan benar-benar menyelidiki latar belakang dan profil dari vendor tersebut. Hal ini perlu dilakukan karena kerja sama ini biasanya dilakukan dalam jangka panjang, dan jika perusahaan salah memilih vendor, akan merugikan bagi perusahaan itu sendiri.

\section{B. Kendala Implementasi ERP di Indonesia}

Paket ERP yang banyak digunakan di Indonesia adalah Oracle Finance dan SAP R/3. Dimana masingmasing paket memiliki kekurangan dan kelebihan. SAP R/3 dikenal dengan kelengkapan modul dan integrasinya yang baik. Selain itu, SAP R/3 juga memiliki kontrol akses yang baik. Sebaliknya, SAP R/3 relatif lebih mahal dibandingkan Oracle Finance dan implemantasinya relative lebih rumit. SAP R/3 lebih banyak digunakan di Indonesia, sehingga pelatihan dan pakar di bidang ini cukup mudah ditemukan. Dalam kenyataannya, beberapa perusahaan menggunakan gabungan dari keduanya untuk menjalankan proses bisnis perusahaan. Selain dua paket ERP diatas, Microsoft Axapta juga cukup banyak digunakan, karena selisih harga yang cukup banyak dari SAP R/3 maupun Oracle.

Pada beberapa kasus implementasi ERP yang ditemui di Indonesia, meskipun perusahaan telah berhati-hati pada saat memilih vendor, pelaksanaan implementasi ERP masih saja menemui banyak kendala. Kendala tersebut terutama dikarenakan ketidaksesuaian modul ERP dengan bisnis proses perusahaan. Terutama di setiap perusahaan Indonesia yang memiliki kebutuhan sistem yang relatif rumit dan sangat unik. Misalnya kebutuhan perusahaan akan pencatatan transaksi dengan valas, perhitungan pajak jual beli, promo penjualan yang beraneka ragam dan lain sebagainya.

Kebutuhan akan customize pada paket ERP yang tidak benar-benar dikuasai oleh vendor, menyebabkan hasil implementasi tidak sesuai dengan kebutuhan perusahaan, baik karyawan maupun top management. Oleh karena itu, dalam tahap perubahan sistem perusahaan ke ERP, sebaiknya perusahaan mencari pendapat dari pihak ketiga, misalnya praktisi atau konsultan IT yang bersifat independen, untuk menghindari conflict of interest antara vendor dan perusahaan.

Masalah lain yang mungkin terjadi adalah kebiasaan orang Indonesia yang malas mendokumentasikan apa saja yang sudah dilakukan [11]. Hal ini menyebabkan melekatnya informasi pada beberapa orang saja, dan ketika orang itu pergi, informasi penting hilang. Demikian juga dengan kontrak, sebaiknya kontrak dengan vendor dibuat sedetail mungkin, untuk menghindari masalah di kemudian hari. Hal-hal yang harus dipersiapkan untuk perubahan sistem ke ERP juga harus dibahas, misalnya bagaimana dengan pemindahaan data dari sistem lama ke ERP, pengaturan data dari berbagai DBMS yang sebelumnya digunakan, waktu pelaksanaan, penalty jika terjadi keterlambatan, baik dari perusahaan dan vendor, dan lain sebagainya.

Vendor yang menyediakan paket ERP di Indonesia antara lain adalah IFS, PT Krakatau Information Technology, PT Abas Information System, PT Aksesa Sistimindo Pratama, PT Mincom Indoservices, Global Business Solution, dan lain sebagainya. Sedangkan perusahaan yang telah mengimplementasikan ERP antara lain adalah Olympic Group, PP London Sumatra, Tbk, Jakarta International Container Terminal, Petrokimia Gresik, SOHO Group, PT PAL, PT Pupuk Sriwidjaya, Bukit Muria Jaya, Sumi Rubber Indonesia, dan perusahaan lainnya [12].

Enterprise Resource Planning (ERP) sistem memiliki beberapa keterbatasan. Sebagai bisnis yang 
terus tumbuh dalam suatu organisasi, aplikasi perangkat lunak yang berbeda diperlukan untuk mengelola informasi di banyak bidang seperti sumber daya manusia, penggajian, keuangan dan administrasi. Pembelian, instalasi dan pemeliharaan beberapa jenis aplikasi perangkat lunak merupakan tantangan untuk perkembangan bisnis. Sistem ERP yang tradisional masih terbatas dalam beberapa pengguna aksesibilitas, kinerja dan ketersediaan sumber daya [13].

Pada akhirnya, tidak semua perusahaan membutuhkan ERP pada pelaksanaan proses bisnisnya. Perusahaan bisa membeli paket ERP secara lengkap, per modul atau membangun sistemnya sendiri, sesuai dengan kebutuhannya, tergantung pada skala kompleksitas proses bisnis perusahaan, disesuaikan dengan dana yang tersedia, personel yang siap menghadapi perubahan yang akan terjadi dengan adanya sistem baru, dan yang paling penting, dukungan dari semua pihak dalam perusahaan. Untuk itu, dibutuhkan suatu teknologi baru yang dapat membantu perusahaan-perusahaan di Indonesia tetap dapat menggunakan aplikasi ERP baik secara lengkap maupun hanya untuk modul-modul yang sesuai dengan proses bisnis perusahaan dengan biaya yang lebih ringan. Cloud Computing merupakan salah satu solusi teknologi yang memungkinkan untuk implementasi ERP di Indonesia.

\section{USULAN PEMANFAATAN CLOUD COMPUTING UNTUK ERP}

Lingkungan cloud computing menyediakan fleksibilitas yang besar dan ketersediaan sumber daya komputasi dengan biaya lebih rendah. Ini merupakan teknologi baru yang membuka era baru e-service di berbagai disiplin ilmu termasuk dalam menyajikan aplikasi inovatif untuk ERP (Enterprise Resource Planning).

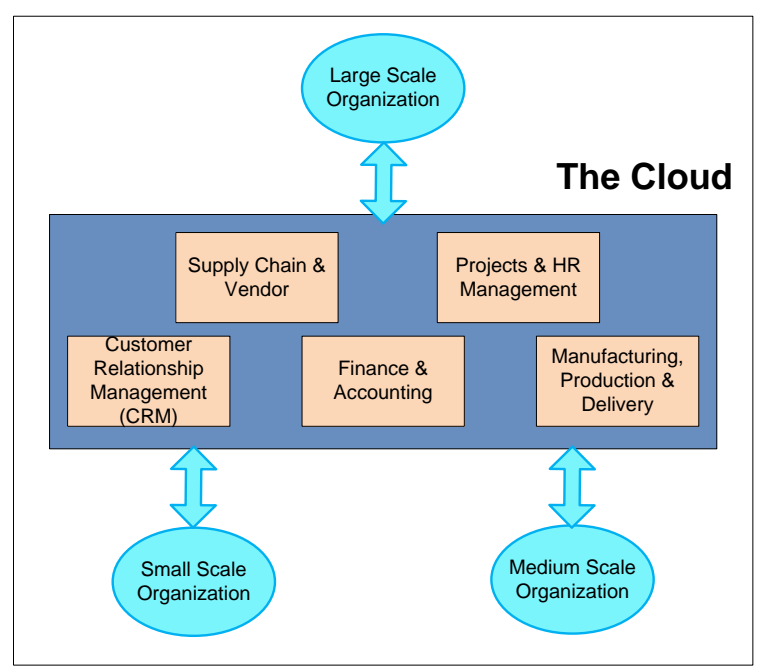

Gambar 4. Service Provided By an ERP Cloud [13]

Usulan kerangka kerja pemanfaatan cloud computing untuk ERP ditunjukkan oleh gambar 4 . Gambar tersebut menunjukkan layanan ERP yang disediakan di cloud yang selanjutnya diistilahkan dengan ERP Cloud. ERP Cloud menginstal aplikasi
ERP pada infrastruktur cloud (misalnya server di pusat data) sehingga mereka dapat diakses oleh suatu perusahaan melalui koneksi jaringan [14]. Oleh karena itu, dengan teknologi ini, manajer proyek tidak perlu khawatir tentang instalasi, upgrade dan pemeliharaan aplikasi dalam organisasi mereka. Selain itu, ERP Cloud menyediakan teknologi untuk perusahaan dengan biaya yang efektif serta sumber daya terukur dengan aplikasi yang multitenant aksesibilitas. Perusahaan dapat mengurangi biaya investasi untuk IT dengan jangka waktu Return of Investment (ROI) yang lebih pendek daripada membeli peralatan dan aplikasi perangkat lunak yang baru. Hal ini penting terutama untuk usaha kecil dan menengah di mana anggaran terbatas.

\section{A. Layanan Cloud Computing}

Terdapat tiga macam pemodelan layanan dari cloud computing yaitu infrastructure as a service (IaaS), platform as a service (PaaS), dan software as a service (SaaS). Pada IaaS, beberapa server yang diletakkan dalam cloud dengan alamat IP yang unik dan sejumlah harddisk untuk menyimpan data. Pengguna menggunakan Application Program Interface (API) untuk dapat mengakses, menyalakan dan mematikan, serta mengkonfigurasi virtual server dan harddisk. PaaS pada cloud didefinisikan sebagai perangkat lunak yang terhubung pada infrastruktur penyedia jasa layanan cloud computing. Contohnya adalah force.com dan GoogleApps. Pada SaaS, penyedia jasa memasok infrastruktur berupa perangkat keras, produk perangkat lunak, dan berhubungan dengan pengguna melalui portal front-end. SaaS memiliki pasar yang sangat luas [2].

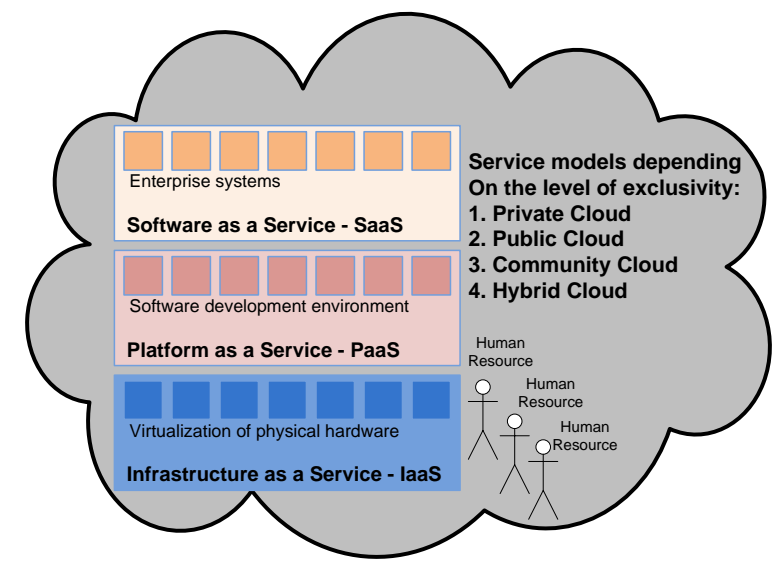

Gambar 5. Level Model for Cloud computing [7]

Gambar 5 di atas merepresentasikan model layanan cloud computing untuk Sistem ERP. Berikut penjelasan 3 model layanan tersebut:

\section{1) IaaS untuk sistem ERP}

IaaS (Infrastucture-as-a-Service) menyediakan layanan penyediaan sumber daya komputasi dari penyedia layanan cloud. Dengan menggunakan IaaS untuk pengoperasian sistem ERP perusahaan, pengguna menyewa sumber daya komputasi dari penyedia layanan cloud. Dalam pengaturan ini 
perusahaan pengguna masih bisa bebas memilih vendor ERP dari sistem ERP dan membeli lisensi untuk perangkat lunak. Pasar sudah menunjukkan bahwa ini akan menjadi model operasi yang layak dimana vendor ERP dan penyedia layanan cloud cenderung bersatu menawarkan layanan gabungan untuk perusahaan pengguna. Integrasi vertikal terjadi ketika vendor ERP menawarkan IaaS sendiri dan menjadi penyedia layanan cloud.

\section{2) PaaS untuk sistem ERP}

PaaS (Platform-as-a-Service) merupakan tingkat kedua dari model layanan cloud computing namun model layanan ini tidak direkomendasikan untuk penyediaan suatu Sistem ERP. Platform layanan menyediakan sumber daya di lingkungan software yang telah ditentukan memang menarik untuk pengembangan perangkat lunak, pengujian, atau distribusi perangkat lunak namun tidak untuk operasi yang sebenarnya dari sistem ERP.

\section{3) SaaS untuk sistem ERP}

Dalam model SaaS (Software-as-a-Service), sistem ERP disediakan oleh penyedia layanan cloud. Peran penyedia layanan cloud dan vendor ERP digabung dalam pengaturan ini (Integrasi vertikal). Beberapa vendor ERP tradisional memiliki dan mengembangkan versi baru yang dapat digunakan dalam cloud (misalnya SAP Business ByDesign, Abacus vi). Hal ini memungkinkan perusahaan pengguna untuk memilih model operasi yang disukai, misalnya menjalankan perangkat lunak ERP di internal cloud mereka sendiri atau dalam external private cloud.

\section{B. Faktor-faktor yang Mendorong Cloud Computing untuk Sistem ERP}

Ada beberapa faktor yang mendorong adopsi layanan komputasi awan, antara yaitu biaya, fleksibilitas dan skalabilitas [1]. Identifikasi preferensi konsumen untuk atribut layanan cloud adalah hal yang penting termasuk mengungkapkan kepentingan relatif dari atribut yang berbeda dari layanan cloud. Demikian juga pentingnya mengidentifikasi manfaat dan risiko perspektif dari pengguna [15].

Adopsi SaaS dapat dilihat dari tiga teoritis perspektif yaitu teori biaya transaksi, teori sumber daya, dan teori tentang semua perilaku yang sebelumnya telah diterapkan untuk mempelajari keputusan IT outsourcing termasuk adopsi perilaku perusahaan [16].

\section{ERP sebagai SaaS yang Menguntungkan Usaha Kecil Menengah}

SaaS dipromosikan oleh penyedia TI menjadi relevan untuk UKM (Usaha Kecil dan Menengah) yang masih memiliki kekurangn kemampuan dan sumber daya TI. Cloud computing memungkinkan UKM untuk menggunakan sistem ERP karena fleksibilitas dimana UKM cukup membayar layananlayanan yang mereka butuhkan saja sehingga membantu mengatasi kesulitan ekonomi mereka untuk investasi TI yang besar [17].

\section{Tantangan Layanan Cloud Computing untuk Sistem ERP}

Ada beberapa tantangan yang masih perlu diatasi sebelum cloud computing akan menjadi paradigma terkemuka dalam konsumsi TI. Hambatan besar bagi adopsi cloud computing adalah interoperabilitas antara penyedia layanan cloud yang berbeda dan kurangnya sebuah platform industri.

Salh satu perbedaan cloud computing dengan jasa pelayanan tradisional TI adalah tidak adanya komitmen jangka panjang di sisi konsumen, memungkinkan mereka untuk beralih ke penyedia layanan cloud yang lain dengan biaya lebih sedikit atau tidak ada. Dalam prakteknya, pengguna mungkin enggan terikat dan terkena biaya switching yang tinggi oleh penyedia yang menggunakan format proprietary untuk menyimpan data mereka.

Cloud computing dapat naik ke tingkat platform industri jika perusahaan penyedia cloud mau membuka teknologi mereka untuk pemain industri lainnya, termasuk complementor's dan pesaing yang berpotensi. Perusahaan penyedia cloud tidak hanya menggunakan web sebagai layanan alternatif serta mau membiayai mekanisme yang digunakan untuk menjadi paket produk perangkat lunak [18].

\section{PENUTUP}

\section{A. Kesimpulan}

Dengan adanya Aplikasi Cloud computing akan menguntungkan perusahaan kecil karena dapat menurunkan hambatan umum terutama berkaitan dengan biaya investasi yang besar untuk penggunaan Sistem ERP pada umumnya. Usaha Kecil Menengah (UKM) dapat memiliki akses penuh atas sistem ERP yang sesuai dengan proses bisnis perusahaan tanpa perlu membeli keseluruhan aplikasi ERP atau menyewa konsultan TI yang mahal.

Dengan kondisi Indonesia yang masih didominasi oleh perusahaan skala kecil dan menengah maka di Indonesia sangat di perlukan pemanfaatan jasa layanan could computing untuk ERP perusahaan sehingga semakin banyak perusahaan yang memanfaatkan aplikasi ERP dengan biaya yang lebih ringan.

\section{B. Saran}

Sementara pasar untuk cloud computing terus berkembang, perusahaan baik disarankan untuk mulai berpikir merumuskan strategi bisnis berbasis cloud computing.

Pemerintah juga diharapkan mulai memikirkan tentang regulasi dari pemanfaatan cloud computing terutama untuk sistem ERP Perusahaan di Indonesia.

\section{DAFTAR PUSTAKA}

[1] OECD, "OECD Information Technology Outlook 2010," 2010. [Online]. Available: 
http://dx.doi.org/10.1787/it_outlook-2010-en. [Accessed 2911 2010].

[2] J. Won Park and N.-Y. Lee, "A Conceptual Model of ERP for Small and Medium-Size Companies Based on UML," IJCSNS International Journal of Computer Science and Network Security, vol. 6, no. 5A, pp. 4243, 2006.

[3] C. Barnatt, A Brief Guide to Cloud Computing: An Essential Introduction to the Next Revolution in Computing, London: Robinson, 2010.

[4] A. Nastiti, Perkembangan Cloud computing di Indonesia, Waena, 2010.

[5] A. Velte and T. a. E. R. Velte, Cloud Computing: A Practical Approach, New York: McGraw-Hill, 2010.

[6] B. a. H. J. Iyer, "Preparing for the Future: Understanding the Seven Capabilities of Cloud Computing ," MIS Quarterly Executive, vol. 9 (2), pp. 117-131, 2010.

[7] P. Schubert and Femi Adisa, "Cloud Computing for Standard ERP Systems: Reference Framework and Research Agenda," Journal of Informatic, Vols. 1-16, 2011.

[8] P. Mell and T. Grance, "The NIST Definition of Cloud Computing," NIST Website (National Institute of Standards and Technology), 2009. [Online]. Available: http://csrc.nist.gov/groups/SNS/cloudcomputing/clouddef-v15.doc. [Accessed 05 Desember 2010].

[9] N. Gibson, C. Holland and B. Light, "Enterprise Resource Planning : A business approach to systems developmen," Proceedings of the 32nd Annual Hawaiii International Conference on System Sciences, 1999.

[10] A. Priandoyo, "Kompetisi aplikasi ERP di Indonesia," 2007 . [Online]. Available: http://priandoyo.wordpress.com/2007/03/06/kompetis i-aplikasi-erp-di-indonesia-second-layer/ . [Accessed 31 May 2009].

[11] Andreas, "Dua Tahun Ribet Bersama Implementasi
ERP , Axapta," 2007. [Online]. Available: http://agorsiloku.wordpress.com/2007/11/25/duatahun-ribet-bersama-implementasi-erp-axapta-1/ . [Accessed 31 May 2009].

[12] I. Indonesia. [Online]. Available: http://www.ifsworld.com/id/news_events/our_custom ers/default.asp\#. [Accessed 31 May 2009].

[13] Youssef and A. E, "Exploring Cloud Computing Services and Applications," Journal of Emerging Trends in Computing and Information Sciences, $\mathrm{p}$. 838, 2012.

[14] N. Robinson, L. Valeri, J. Cave, T. Starkey, H. Graux, S. Creese and P. Hopkins, "The Cloud: Understanding the Security, Privacy and Trust Challenges," RAND Corporation, 2010. [Online]. Available: http://cordis.europa.eu/fp7/ict/security/docs/thecloudunderstanding-security-privacy-trustchallenges 2010_en.pdf.

[15] P. Koehler, A. Anandasivam and M. and Dan, "Cloud Services from a Consumer Perspective"," AMCIS 2010 Proceedings, 2010.

[16] A. Benlian and T. a. B. P. Hess, "Drivers of SaaSAdoption - An Empirical Study of Different Application Types, Business \& Information Systems Engineering," vol. 5, pp. 357-369, 2009.

[17] N. Sultan, "Cloud computing for education: A new dawn," International Journal of Information Management, vol. 30 (2), pp. 109-116, 2010.

[18] M. Cusumano, "Technology Strategy and Management: Cloud computing and SaaS as New Computing Platforms," Communications of the ACM, vol. 53 (4), pp. 27-29, 2010. 